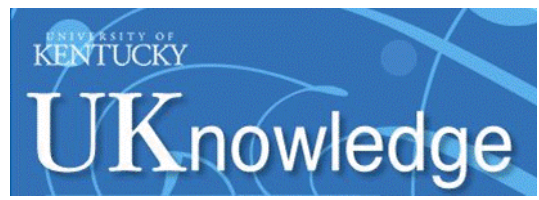

University of Kentucky

UKnowledge

\title{
Progressive Age-Dependence and Frequency Difference in the Effect of Gap Junctions on Active Cochlear Amplification and Hearing
}

\author{
Liang Zong \\ University of Kentucky \\ Jin Chen \\ University of Kentucky, chen.jin@uky.edu \\ Yan Zhu \\ University of Kentucky, yan.zhu@uky.edu \\ Hong-Bo Zhao \\ University of Kentucky, Hong-Bo.Zhao@uky.edu
}

Follow this and additional works at: https://uknowledge.uky.edu/otolaryngology_facpub

Part of the Biochemistry, Biophysics, and Structural Biology Commons, and the Otolaryngology Commons

Right click to open a feedback form in a new tab to let us know how this document benefits you.

\section{Repository Citation}

Zong, Liang; Chen, Jin; Zhu, Yan; and Zhao, Hong-Bo, "Progressive Age-Dependence and Frequency Difference in the Effect of Gap Junctions on Active Cochlear Amplification and Hearing" (2017). Otolaryngology--Head \& Neck Surgery Faculty Publications. 10.

https://uknowledge.uky.edu/otolaryngology_facpub/10

This Article is brought to you for free and open access by the Otolaryngology-Head \& Neck Surgery at UKnowledge. It has been accepted for inclusion in Otolaryngology--Head \& Neck Surgery Faculty Publications by an authorized administrator of UKnowledge. For more information, please contact UKnowledge@lsv.uky.edu. 


\title{
Progressive Age-Dependence and Frequency Difference in the Effect of Gap Junctions on Active Cochlear Amplification and Hearing
}

\author{
Digital Object Identifier (DOI) \\ https://doi.org/10.1016/j.bbrc.2017.05.137 \\ Notes/Citation Information \\ Published in Biochemical and Biophysical Research Communications, v. 489, issue 2, p. 223-227. \\ (C) 2017 Elsevier Inc. All rights reserved.
}

This manuscript version is made available under the CC-BY-NC-ND 4.0 license

https://creativecommons.org/licenses/by-nc-nd/4.0/.

The document available for download is the author's post-peer-review final draft of the article. 


\title{
Progressive age-dependence and frequency difference in the effect of gap junctions on active cochlear amplification and hearing
}

\author{
Liang Zong ${ }^{1,2,{ }^{*}, \text { Jin Chen }}{ }^{1,3,{ }^{*}, \text { Yan Zhu }}{ }^{1}$, and Hong-Bo Zhao ${ }^{1}$ \\ ${ }^{1}$ Dept. of Otolaryngology, University of Kentucky Medical School, Lexington, KY 40536 \\ 2Department of Otolaryngology, Chinese PLA General Hospital, 28 Fuxing Road, Beijing, 100853, \\ P. R. of China \\ ${ }^{3}$ Department of Otolaryngology, Tongji Hospital, Huazhong University of Science \& Technology, \\ 1095 Jiefang Avenue, Wuhan 430030, P. R. of China
}

\begin{abstract}
Mutations of Connexin 26 (Cx26, GJB2), which is a predominant isoform in the cochlea, can induce high incidence of nonsyndromic hearing loss. We previously found that targeted-deletion of Cx26 in supporting Deiters cells and outer pillar cells in the cochlea can influence outer hair cell (OHC) electromotility and reduce active cochlear amplification leading to hearing loss, even though there are no gap junction connexin expressions in the auditory sensory hair cells. Here, we further report that hearing loss and the reduction of active amplification in the Cx26 conditional knockout (cKO) mice are progressive and different at high and low frequency regions, first occurring in the high frequency region and then progressively extending to the middle and low frequency regions with mouse age increased. The speed of hearing loss extending was fast in the basal high frequency region and slow in the apical low frequency region, showing a logarithmic function with mouse age. Before postnatal day 25 , there were no significant hearing loss and the reduction of active cochlear amplification in the low frequency region. Hearing loss and the reduction of active cochlear amplification also had frequency difference, severe and large in the high frequency regions. These new data indicate that the effect of gap junction on active cochlear amplification is progressive, but, consistent with our previous report, exists in both high and low frequency regions in adulthood. These new data also suggest that cochlear gap junctions may have an important role in age-related hearing loss.
\end{abstract}

\section{Keywords}

gap junction; Cx26; active cochlear mechanics; DPOAE; deafness; age-related hearing loss

\footnotetext{
Corresponding Author: Hong-Bo Zhao, Ph.D./M.D., Associate Professor, Dept. of Otolaryngology, University of Kentucky Medical Center, 800 Rose Street, Lexington, KY 40536 - 0293, Tel: 859-257-5097 x 82138, Fax: 859-257-5096, hzhao2@uky.edu. Equal contributors

Publisher's Disclaimer: This is a PDF file of an unedited manuscript that has been accepted for publication. As a service to our customers we are providing this early version of the manuscript. The manuscript will undergo copyediting, typesetting, and review of the resulting proof before it is published in its final citable form. Please note that during the production process errors may be discovered which could affect the content, and all legal disclaimers that apply to the journal pertain.
} 


\section{Introduction}

In the mammalian cochlea, outer hair cells (OHCs) can be motile under acoustic/electronic stimulation [1]. This $\mathrm{OHC}$ electromotility acts as an active cochlear amplifier to burst the basilar membrane vibration increasing hearing sensitivity and frequency selectivity [1,2]. This active cochlear amplification is required for normal hearing in mammalians. Knockout of prestin, which is the motor protein of OHC electromotility, induces hearing loss [3,4].

In vivo, OHCs are surrounded by supporting cells. The cochlear supporting cells are wellcoupled by gap junctions [5,6]. Connexin26 (Cx26) and $\mathrm{Cx} 30$ are predominant connexin gap junction isoforms in the inner ear [6-10]. Cx26 (GJB2) mutations can induce hearing loss and account for more than $50 \%$ cases of nonsyndromic hearing loss [6, 11-13]. Connexin expression and gap junctions in the cochlea only exist in non-sensory supporting cells but not in sensory hair cells including OHCs [7,9,14-16]. However, our previous studies demonstrated that gap junctional coupling between cochlear supporting cells can influence OHC electromotility and active cochlear amplification [16], indicating that connexin gap junctions in the cochlea play more broad and important functions in hearing. Our recent studies further demonstrated that knockout of $\mathrm{Cx} 26$ expression in the cochlear supporting cells can affect $\mathrm{OHC}$ electromotility leading to hearing loss [17,18]. Target-deletion of C26 in the cochlear supporting Deiters cells (DCs) and outer pillar cells (OPCs), which constrain OHCs standing on the basilar membrane, can reduce OHC electromotility and active cochlear amplification and cause hearing loss [17]. In this study, we further found that the hearing loss and reduction of active cochlear amplification are progressive, extending from high-frequency region to low-frequency region with mouse age, and also have difference in high and low frequency regions. The new data demonstrate that gap junction can regulate active cochlear amplification in apical low-frequency region as well as the basal highfrequency region but the regulation in the high-frequency region are more susceptible and vulnerable to be impaired. Our new findings provide a light on why hearing function in high-frequency range is vulnerable to be compromised with aging and noise stress.

\section{Materials and Methods}

\section{Cx26 conditional KO mouse generation and genotyping}

As described in our previous report [17], Prox 1-CreER ${ }^{T 2(+/+)} ; C \times 26^{\text {LoxP(+/-) }}$ mice were generated by crossing of $C \times 26^{\text {loxP/ox } P}$ transgenic mice (EMMA, EM00245) $[19,20]$ with Prox 1-CreER ${ }^{T 2}$ mouse line (Stock No. 022075, Jackson Laboratory, USA) and used for breeding. Mouse genotyping was identified by PCR amplification of tail genomic DNA. Tamoxifen (T5648, Sigma-Aldrich, St. Louis, MO) was administrated to all litters at postnatal day 0 (P0) by intraperitoneal injection $(0.5 \mathrm{mg} / 10 \mathrm{~g} \times 3$ days) [17]. Prox 1 $C r e E R^{T 2(+/)} ; C \times 26^{L o x P(+/+)}$ mice were used as Cx26-Preox1 conditional knockout (cKO) mice and littermates of Prox 1-CreER ${ }^{T 2(+/)} ; C \times 26^{\operatorname{Lox} P(-/-)}$ were used as wild-type (WT) control. All experimental procedures were conducted in accordance with the National Institutes of Health guide for the care and use of Laboratory animals (NIH Publications No. 8023, revised 1978) and the policies of University of Kentucky Animal Care \& Use Committee. 
Auditory brainstem response and distortion product otoacoustic emission measurements

As described in our previous reports $[17,18,20]$, auditory brainstem response (ABR) and distortion product otoacoustic emission (DPOAE) were recorded by use of a Tucker-Davis ABR \& DPOAE workstation with ES-1 high frequency speaker (Tucker-Davis Tech. Alachua, FL). ABR was recorded by stimulation with clicks in alternative polarity and tone bursts (4-40 kHz) in a $5 \mathrm{~dB}$ step and was averaged by 500 times. The ABR threshold was determined by the lowest level at which an ABR can be recognized. For DPOAE recording, the test frequencies were presented by a geometric mean of $\mathrm{f}_{1}$ and $\mathrm{f}_{2}\left[\mathrm{f}_{0}=\left(\mathrm{f}_{1} \times \mathrm{f}_{2}\right)^{1 / 2}\right]$ from $\mathrm{f}_{0}=4$ to $20 \mathrm{kHz}$. The distortion product was recorded from the $\mathrm{L}_{1} / \mathrm{L}_{2}$ level of $60 / 55$ to $25 / 20$ $\mathrm{dB}$ SPL with average of 150 times. A cubic distortion component of $2 \mathrm{f}_{1}-\mathrm{f}_{2}$ was measured.

\section{Immunofluorescent staining and confocal microscopy}

The cochlear tissue preparation and immunofluorescent staining were performed as previously reported $[9,10]$. Monoclonal mouse anti-Cx26 (Cat\# 33-5800), polyclonal rabbit anti-Cx30 (Cat\#71-2200, Invitrogen Corp, Carlsbad, CA), and monoclonal mouse antiprestin (a kind gift from Dr. Jing Zheng at Northwestern University) were used and visualized by secondary Alexa Fluor ${ }^{\circledR} 488$ or 568 conjugated antibodies (Molecular Probes). The staining was observed under fluorescence or confocal laser-scanning microscopes.

\section{Statistical analysis}

Data were plotted by SigmaPlot and statistically analyzed by SPSS (SPSS Inc.; Chicago, IL). Error bars represent SEM.

\section{Results}

\section{Deletion of Cx26 in the cochlea in Cx26-Prox1 cKO mice}

Fig. 1 shows immunofluorescent staining for Cx26 in the cochlea of Cx26-Prox $1 \mathrm{cKO}$ mice. Cx26 labeling in DC and OPC area in Cx26 cKO mice was absent (Fig. 1C-F). However, Cx30 expression still remained in this region (Fig. 1E\&F). Also, Cx26 deletion had no apparent difference along the cochlear sensory epithelium in whole-mounting preparation (Fig. 1D), indicating that there was no apparent difference in Cx26 deletion in low and high frequency region as demonstrated in our previous report [17].

\section{Progress and frequency difference of hearing loss in Cx26-Prox1 cKO mice}

Cx26-Prox1 cKO mice had hearing loss (Fig. 2) as demonstrated in our previous study [17]. However, hearing loss appears progressively age-dependent and difference in low and high frequencies (Figs. 2\&3). At postnatal day 15 (P15), ABR thresholds in both $\mathrm{Cx} 26 \mathrm{cKO}$ and WT mice had no significant difference (Fig. 2A). At P25 (Fig. 2B), there was still no difference in the ABR thresholds between $\mathrm{Cx} 26 \mathrm{cKO}$ and WT mice at middle and low frequencies. However, at $40 \mathrm{kHz}$ high-frequency, $\mathrm{ABR}$ threshold in $\mathrm{Cx} 26 \mathrm{cKO}$ mice was significantly increased to $64.5 \pm 2.41 \mathrm{~dB}$ SPL, increasing about $21.7 \mathrm{~dB}$ SPL in comparison with $42.8 \pm 3.32 \mathrm{~dB}$ SPL in WT mice (Fig. 2B). Then, hearing loss progressively extended to middle and low frequency regions. At P35, ABR threshold at $24 \mathrm{kHz}$ in $\mathrm{Cx} 26 \mathrm{cKO}$ mice was 
significantly increased to $46.3 \pm 3.37 \mathrm{~dB}$ SPL (Fig. $2 \mathrm{C}$ ) and at P45 the ABR threshold at 16 $\mathrm{kHz}$ was significantly increased to $43.5 \pm 1.30 \mathrm{~dB}$ SPL (Fig. 2D). Finally, at P60, the ABR thresholds in $\mathrm{Cx} 26 \mathrm{cKO}$ mice were significantly increased for $8 \mathrm{kHz}$ tone and click stimulation (Fig. 2E).

The speed of hearing loss extending from high frequency to low frequency in Cx $26 \mathrm{cKO}$ mice was fast in the high frequency region and slow in the low frequency region (Fig. 3B). The first time of hearing loss occurrence at frequency could be described by a common logarithmic function: $\log \mathrm{y}(\mathrm{kHz})=2.087-0.0198 * \times($ day $)($ Fig. 3B). The estimated time of hearing loss occurring at $60 \mathrm{kHz}$, which is at the highest frequency region in mouse hearing, is expected at $\sim \mathrm{P} 15.5$, just after mouse hearing starting (P13-14) [20].

The increase of ABR threshold in $\mathrm{Cx} 26 \mathrm{cKO}$ mice is also different in low and highfrequency regions (Figs. 2 and 3A). In the frequency region $>24 \mathrm{kHz}, \mathrm{ABR}$ threshold was increased largely (Fig. 3A). At P60, ABR threshold increase in $>24 \mathrm{kHz}$ frequency regions was about $40 \mathrm{~dB}$ SPL, whereas the increase of ABR threshold at $<16 \mathrm{kHz}$ frequency region was only about $10 \mathrm{~dB}$ SPL (Fig. 3A).

The degree of hearing loss was also progressively increased with mouse age (Fig. 3C). For example, at $24 \mathrm{kHz}, \mathrm{ABR}$ threshold was significantly increased by $\sim 10,20$, and $40 \mathrm{~dB}$ SPL at P35, P45, and P60, respectively. At $16 \mathrm{kHz}$, the increase in ABR threshold at P60 in Cx26 cKO mice was 10.1 $\pm 3.77 \mathrm{~dB}$ SPL (Fig. 3C). However, the increase of ABR threshold at P80 was increased to $34.4 \pm 7.15 \mathrm{~dB}$ SPL (Fig. 3C). The maximum of ABR threshold increase in Cx26 cKO mice was about $40 \mathrm{~dB}$ SPL (Figs. 2\&3).

\section{Progressive reduction of active cochlear amplification in Cx26 cKO mice}

As mentioned above, mammalian hearing relies upon active cochlear amplification.

Deficiency of active cochlear amplification can induce hearing loss. Fig. 4 shows that active cochlear amplification as measured by DPOAE in Cx26 cKO mice was reduced. The reduction was also progressive. Before $\mathrm{P} 25$, there was no any DPOAE reduction detectable in the tested frequencies in Cx26 cKO mice (Fig. 4A-D). At P30, DPOAEs at 16 and 20 $\mathrm{kHz}$ in $\mathrm{Cx} 26 \mathrm{cKO}$ mice were significantly reduced (Fig. 4C\&D). The reduction was also progressively extended to the low-frequency (Fig. 4E). At P80, the significant reduction of DPOAE in Cx26 cKO mice was detected at $8 \mathrm{kHz}$ (Fig. 4B\&E). However, the reduction was small $(-5.70 \pm 2.27 \mathrm{~dB})$ in comparison with those at 16 and $20 \mathrm{kHz}$, at which the reduction was $-20.4 \pm 6.09 \mathrm{~dB}$ and $-27.1 \pm 4.19 \mathrm{~dB}$, respectively (Fig. 4E).

\section{Discussion}

We previously reported that gap junctions between DCs can mediate OHC electromotility [16]. Targeted-deletion of Cx26 in DCs and OPCs could shift OHC electromotility and reduced DPOAE leading to hearing loss [17]. In this study, we further found that hearing loss and the reduction of active cochlear amplification in Cx26-Prox $1 \mathrm{cKO}$ mice are agedependent, progressively extending from high-frequency region to low-frequency region with mouse age (Figs. 2-4). Hearing loss and the reduction at high and low frequency regions were also different, severe at high frequencies (Figs. 2-4). These new findings 
suggest that Cx26 deficiency can reduce active cochlear amplification inducing hearing loss in both high and low frequencies.

In this study, we found that the hearing loss and the reduction of DPOAE in Cx26-Prox1 cKO mice were more apparent at middle and high frequency regions in comparison with those in the low frequency region (Figs. 2-4). This corresponds well with the gradient expression of Cx26 at the cochlear sensory epithelium. We previously found that Cx26 expression at the high frequency basal turn is less than that at the low-frequency apical turn, and that $\mathrm{Cx} 26$ function at the high frequency region is susceptible to be impaired [9]. DPOAE reduction and hearing loss appeared severe at high frequencies (Figs. 2-4). This may also imply that gap junctions between supporting cells at high frequency region are more important and critical than those at low frequency region for active cochlear amplification.

Hearing loss and the reduction of active cochlear amplification in Cx26-Prox $1 \mathrm{cKO}$ mice first occurred at the high-frequency region, then progressively extending to middle and low frequency regions with age (Figs. 2-4). At $<\mathrm{P} 25$, there was no hearing loss in middle and low frequency ranges in Cx26-Prox $1 \mathrm{cKO}$ mice, except $40 \mathrm{kHz}$ (Figs. 2-3). DPOAE also had no significant reduction in the tested frequencies (4-20 kHz) (Fig. 4). However, at P45, Cx26-Prox 1 cKO mice had significant increase in ABR threshold and decrease in DPOAE at $16 \mathrm{kHz}$ middle frequency region (Figs. 2-4). We further found that the speed of hearing loss extending from high-frequency to low-frequency could be described as a logarithmic function, showing a linear function in the plot with logarithmic frequency scale (Fig. 3B). This corresponds with logarithmic changes of frequency in the cochlear sensory epithelium.

The reduction of DPOAE was large at the high stimulus levels and increased as the sound intensity was increased (Fig. 4F). The reduction also first occurred at high intensity region (Fig. 4F). This implies that the regulation of gap junction between cochlear supporting on active cochlear amplification have a critical role in the high sound intensity region, too. Indeed, it has been reported that supporting cells can reduce cochlear sensitivity as shown in intense sound stimulation [21-22].

In previous study, we reported that this $\mathrm{Cx} 26 \mathrm{cKO}$ mice have no significant hair cell degeneration and normal endocochlear potential (EP), which is a driving force for $\mathrm{K}+$ ions passing through mechanical transduction channels producing auditory receptor currents [17]. The cochlea in Cx26 cKO mice also displayed normal development and structure (Fig. 1C) [17]. As mentioned above, connexin gap junctions in the cochlea only exist in the cochlear supporting cells not in the hair cells [7,9]. Also, there is no direct electrical coupling between supporting cells and hair cells [14-16]. So far, the mechanism underlying the effect of connexin gap junctions on $\mathrm{OHC}$ electromotility and active cochlear amplification still remains unclear. In previous study, we reported the effect of gap junctions between cochlear supporting cells on $\mathrm{OHC}$ electromotility through the direct mechanical coupling [17]. It has been reported that connexins have non-channel function to influence cell cytoskeleton formation, besides formation of gap junctional channels [23]. Whether Cx26 deficiency can reduce cytoskeleton formation in the cochlear supporting cells needs to be further investigated in future. 
In the clinic, $\mathrm{Cx} 26$ mutations can cause progressive late-onset hearing loss and congenital deafness $[6,12,13]$. Recent studies demonstrated that congenital deafness is associated with Cx26 deficiency induced cochlear developmental disorders [20,24-26], whereas late-onset hearing loss may resulted from the reduction of active cochlear amplification, even OHCs have no connexin expressions $[17,18,26]$. However, the commonly assumed $\mathrm{K}^{+}$-recycling defect is not a primary deafness mechanism for Cx26 deficiency induced hearing loss [26]. In this experiment, we found that the effect of gap junction on active cochlear amplification and hearing is progressive, extending from basal high-frequency region to apical lowfrequency region with mouse age (Figs. 2-4). The increase in ABR thresholds in Cx26 cKO mice was also increased as muse age increased (Fig. 3A\&C). These new data further indicate that cochlear gap junctions may also play an important role in aging-related hearing loss and noise-induced hearing loss.

\section{Acknowledgments}

This work was supported by NIH R56 DC 015019 to HBZ, the National Natural Science Foundation of China (No. $81600795)$ to LZ and (No. 81500791) to JC.

\section{References}

1. Brownell WE, Bader CR, Bertrand D, Ribaupierre Y. Evoked mechanical responses of isolated cochlear outer hair cells. Science. 1985; 227:194-196. [PubMed: 3966153]

2. Ashmore J. Cochlear outer hair cell motility. Physiol. Rev. 2008; 88:173-210. [PubMed: 18195086]

3. Zheng J, Shen W, He DZ, Long KB, Madison LD, Dallos P. Prestin is the motor protein of cochlear outer hair cells. Nature. 2000; 405:149-155. [PubMed: 10821263]

4. Liberman MC, Gao J, He DZ, Wu X, Jia S, Zuo J. Prestin is required for electromotility of the outer hair cell and for the cochlear amplifier. Nature. 2002; 419:300-304. [PubMed: 12239568]

5. Zhao HB, Kikuchi T, Ngezahayo A, White TW. Gap junctions and cochlear homeostasis. J. Memb. Biol. 2006; 209:177-186.

6. Wingard JC, Zhao HB. Cellular and Deafness Mechanisms Underlying Connexin Mutation-Induced Hearing Loss - A Common Hereditary Deafness. Front. Cell Neurosci. 2015; 9:202. [PubMed: 26074771]

7. Kikuchi T, Kimura RS, Paul DL, Adams JC. Gap junctions in the rat cochlea: immunohistochemical and ultrastructural analysis. Anat. Embryol. 1995; 191:101-118. [PubMed: 7726389]

8. Forge A, Becker D, Casalotti S, Edwards J, Marziano N, Nevill G. Gap junctions in the inner ear: comparison of distribution patterns in different vertebrates and assessement of connexin composition in mammals. J. Comp. Neurol. 2003; 467:207-231. [PubMed: 14595769]

9. Zhao HB, Yu N. Distinct and gradient distributions of connexin26 and connexin30 in the cochlear sensory epithelium of guinea pigs. J. Comp. Neurol. 2006; 499:506-518. [PubMed: 16998915]

10. Liu YP, Zhao HB. Cellular characterization of Connexin26 and Connnexin30 expression in the cochlear lateral wall. Cell Tissue Res. 2008; 333:395-403. [PubMed: 18581144]

11. Kelsell DP, Dunlop J, Stevens HP, Lench NJ, Liang JN, Parry G, Mueller RF, Leigh IM. Connexin 26 mutations in hereditary non-syndromic sensorineural deafness. Nature. 1997; 387:80-83. [PubMed: 9139825]

12. Castillo FJ, Castillo I. The DFNB1 subtype of autosomal recessive non-syndromic hearing impairment. Front. Biosci. 2011; 17:3252-3274.

13. Chan DK, Chang KW. GJB2-associated hearing loss: systematic review of worldwide prevalence, genotype, and auditory phenotype. Laryngoscope. 2014; 124:E34-53. [PubMed: 23900770]

14. Zhao HB, Santos-Sacchi J. Auditory collusion and a coupled couple of outer hair cells. Nature. 1999; 399:359-362. [PubMed: 10360573] 
15. Zhao HB. Directional rectification of gap junctional voltage gating between Deiters cells in the inner ear of guinea pig. Neurosci. Lett. 2000; 296:105-108. [PubMed: 11108992]

16. Yu N, Zhao HB. Modulation of outer hair cell electromotility by cochlear supporting cells and gap junctions. PLoS One. 2009; 4:e7923. [PubMed: 19936276]

17. Zhu Y, Liang C, Chen J, Zong L, Chen GD, Zhao HB. Active cochlear amplification is dependent on supporting cell gap junctions. Nat. Commun. 2013; 4:1786. [PubMed: 23653198]

18. Zhu Y, Chen J, Liang C, Zong L, Chen J, Jones RO, Zhao HB. Connexin26 (GJB2) deficiency reduces active cochlear amplification leading to late-onset hearing loss. Neuroscience. 2015; 284:719-729. [PubMed: 25451287]

19. Cohen-Salmon M, Ott T, Michel V, Hardelin JP, Perfettini I, Eybalin M, Wu T, Marcus DC, Wangemann P, Willecke K, Petit C. Targeted ablation of connexin26 in the inner ear epithelial gap junction network causes hearing impairment and cell death. Curr. Biol. 2002; 12:1106-1111. [PubMed: 12121617]

20. Liang C, Zhu Y, Zong L, Liu GJ, Zhao HB. Cell degeneration is not a primary causer for Cx26 deficiency associated hearing loss. Neurosci. Lett. 2012; 528:36-41. [PubMed: 22975134]

21. Fridberger A, Flock A, Ulfendahl M, Flock B. Acoustic overstimulation increases outer hair cell $\mathrm{Ca}^{2+}$ concentrations and causes dynamic contractions of the hearing organ. Proc. Natl. Acad. Sci. USA. 1998; 95:7127-7132. [PubMed: 9618550]

22. Flock A, Flock B, Fridberger A, Scarfone E, Ulfendahl M. Supporting cells contribute to control of hearing sensitivity. J. Neurosci. 1999; 19:4498-4507. [PubMed: 10341250]

23. Hervé JC, Derangeon M, Sarrouilhe D, Giepmans BN, Bourmeyster N. Gap junctional channels are parts of multiprotein complexes. Biochim. Biophys. Acta. 2012; 1818:1844-1865. [PubMed: 22197781]

24. Chen J, Chen J, Zhu Y, Liang C, Zhao HB. Deafness induced by Connexin 26 (GJB2) deficiency is not determined by endocochlear potential (EP) reduction but is associated with cochlear developmental disorders. Biochem. Biophys. Res. Commun. 2014; 448:28-32. [PubMed: 24732355]

25. Zhu Y, Zong L, Mei L, Zhao HB. Connexin26 gap junction mediates miRNA intercellular genetic communication in the cochlea and is required for inner ear development. Sci. Rep. 2015; 5:15647. doi: 0.1038/srep15647. [PubMed: 26490746]

26. Zhao HB. Hypothesis of $\mathrm{K}^{+}$-recycling defect is not a primary deafness mechanism for $\mathrm{Cx} 26$ (GJB2) deficiency. Front. Mol. Neurosci. 2017; 10:162.doi: 10.3389/fnmol.2017.00162 [PubMed: 28603488] 


\section{Highlights}

* Effect of Cx26 KO on active cochlear amplification is age-dependent

* Hearing and amplification progressively reduce from high to low frequency

* Speed of hearing loss extending in frequency is a logarithmic function with age

* Hearing loss and amplification reduction at low and high frequencies are different 

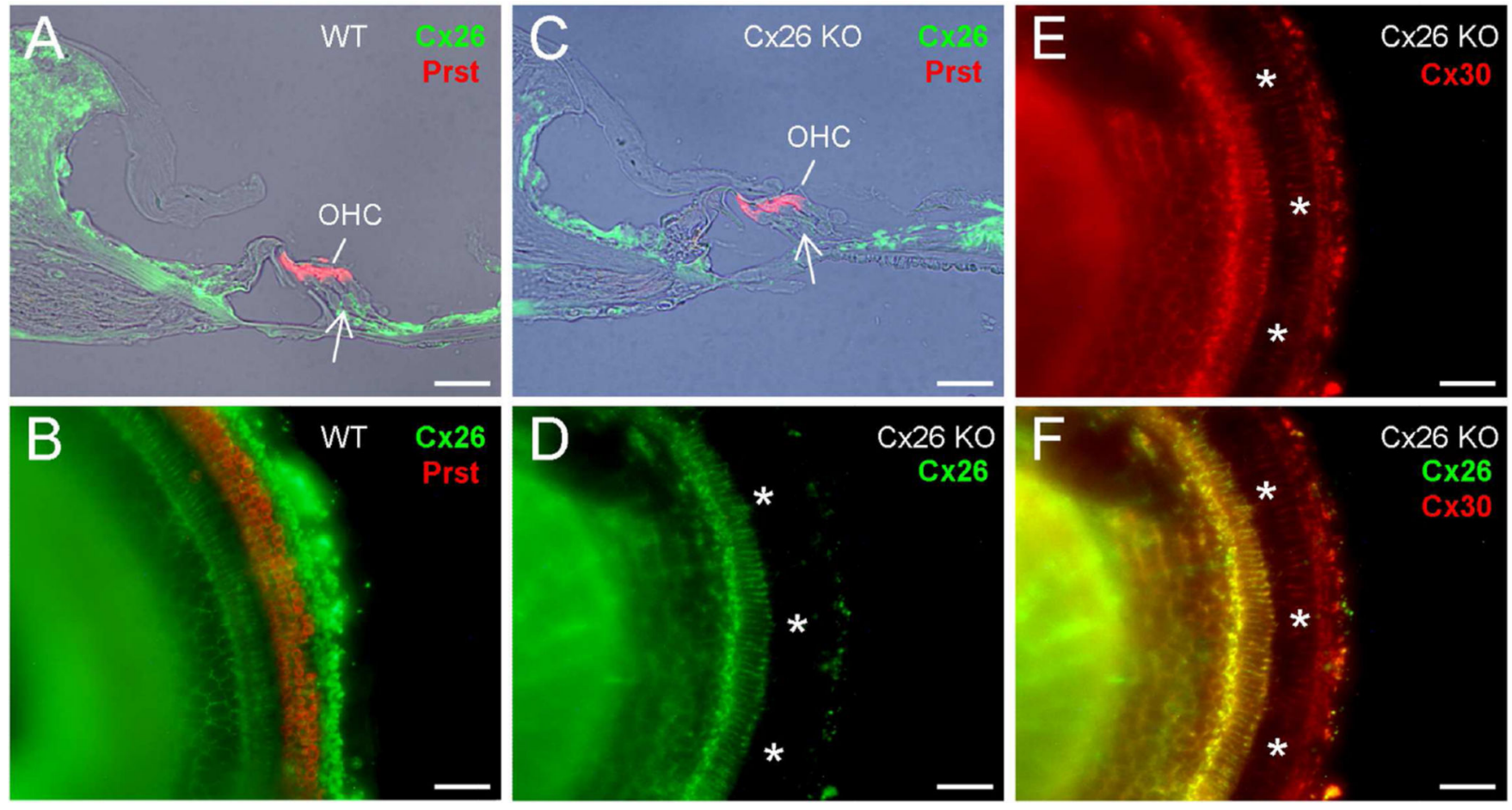

Fig. 1.

Deletion of Cx26 in the cochlea in Cx26-Prox1 cKO mice. A-B: Immunofluorescent staining for Cx26 (green) and prestin (red) in WT mice with the cochlear cross-section and whole-mounting preparation. Outer hair cells $(\mathrm{OHCs})$ are visualized by prestin labeling. A white arrow indicates Deiters cell (DC) and outer pillar cell (OPC) area. C-F: Immunofluorescent staining of the cochlea for $\mathrm{Cx} 26$ and prestin in the $\mathrm{Cx} 26$-Prox $1 \mathrm{cKO}$ mice. A white arrow in panel $\mathbf{C}$ indicates no $\mathrm{Cx} 26$ labeling in the $\mathrm{DC}$ and $\mathrm{OPC}$ area. White asterisks in panel D-F represent OHC-DC-OPC area in the whole-mounting preparation, in which Cx26 labeling is absent while Cx30 labeling remains. Scale bar $=50 \mu \mathrm{m}$. 

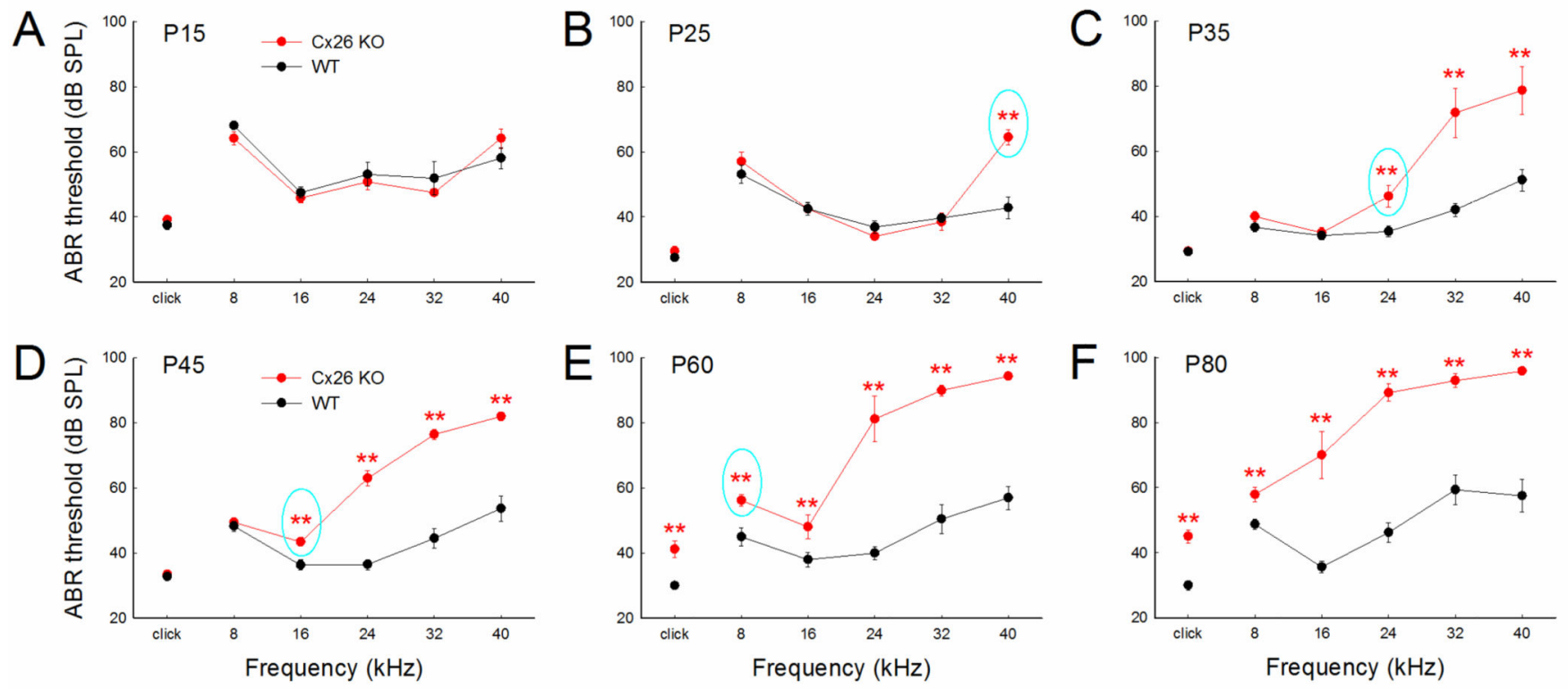

Fig. 2.

Progressive increase in ABR thresholds in Cx26-Prox $1 \mathrm{cKO}$ mice. A-F: The thresholds of $\mathrm{ABR}$ at different postnatal days (P15-80) recorded from 6-12 ears in Cx26 cKO mice and 8-16 ears in WT mice. Cyan color circles indicate the earliest occurrence of significant increase in ABR thresholds in different frequencies in Cx $26 \mathrm{cKO}$ mice. Hearing loss occurs early in high-frequency region and then extends to the low-frequency region. $* *$ : $\mathrm{P}<0.01$, one-way ANOVA with a Bonferroni correction. 

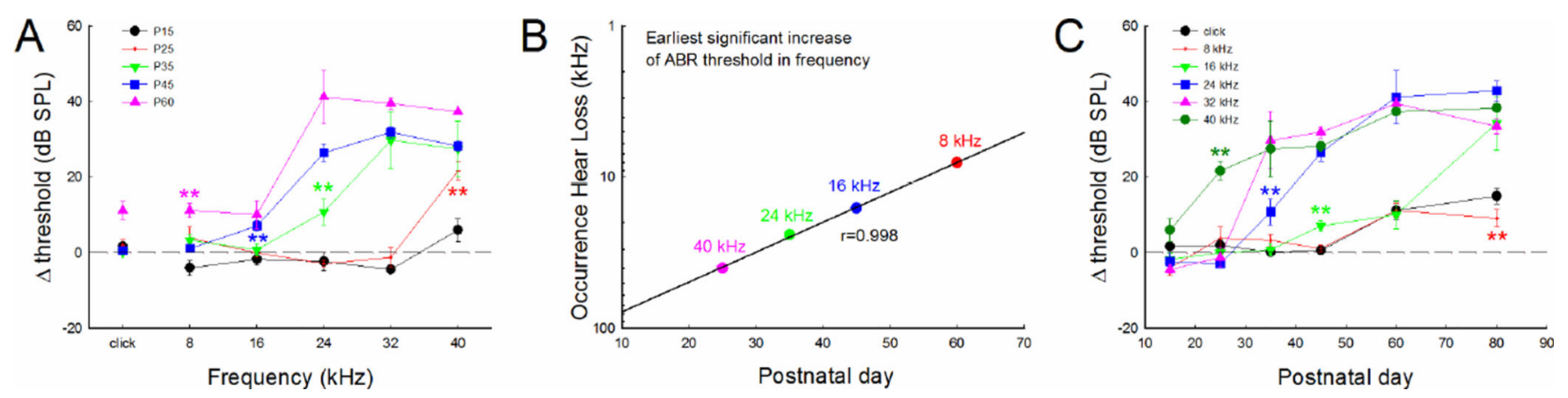

Fig. 3.

Progressive hearing loss extending speed and frequency difference of hearing loss in Cx26Prox 1 cKO mice. A: ABR threshold increase at different frequencies in Cx26 cKO mice. Asterisks with different colors represent the earliest occurring time of significant increase in ABR thresholds at different frequencies. B: The speed of progressive hearing loss from high-frequencies to low-frequencies in $\mathrm{Cx} 26 \mathrm{cKO}$ mice. Earliest occurrence of significant increases in ABR thresholds at different frequencies was plotted with mouse age. A solid line represents common logarithmic function fitting, showing as linear fitting in the plot with a common logarithmic scale in frequency: $\log \mathrm{y}$ (Frequency, $\mathrm{kHz})=2.087-0.0198 * \times$ (postnatal day), $r=0.998$. C: Progressive increases in ABR thresholds at different frequencies in $\mathrm{Cx} 26 \mathrm{cKO}$ mice with mouse age. Asterisks with different colors represent the earliest occurring time of significant increase in ABR thresholds at different frequencies. **: $\mathrm{P}<0.01$, one-way ANOVA with a Bonferroni correction. 

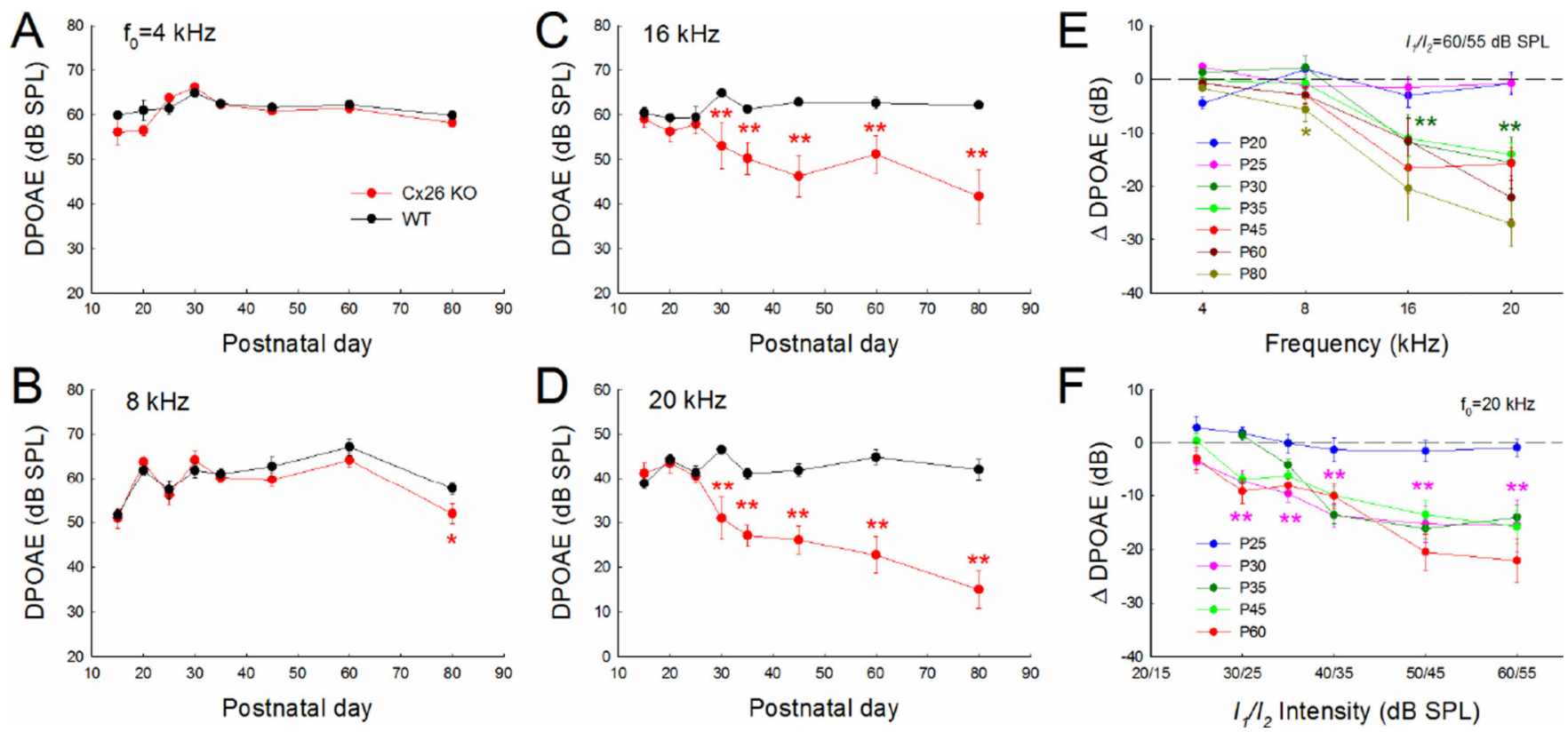

Fig. 4.

Progressive reduction of acoustic emission in Cx26-Prox $1 \mathrm{cKO}$ mice. DPOAE $\left(2 \mathrm{f}_{1}-\mathrm{f}_{2}\right)$ at different postnatal days (P15-80) recorded from Cx26 cKO mice (6-24 ears) and WT mice (6-30 ears). A-D: Progressive reduction of DPOAE in Cx26-Prox $1 \mathrm{cKO}$ mice in different frequencies. The reduction first occurs in the high-frequency region and then extends to the low-frequency region. Before P25, there is no any reduction in DPOAE in the recording frequency regions. However, at P30 afterward, significant reduction in DPOAE can be seen in 8-20 kHz (panel B-D). E: Decrease of DPOAE in Cx26 cKO mice (referring to those in WT mice) at different frequencies and postnatal days. Different color asterisks represent the earliest detection of significant reduction in DPOAE at different frequencies. F: Decrease of DPOAE in Cx26 cKO mice at different stimulus sound intensities (I/O plot) and different postnatal days. The reduction of DPOAE in Cx26 cKO mice appears large in highintensities. One and two asterisks represent $\mathrm{P}<0.05$ and 0.01 (one-way ANOVA with a Bonferroni correction), respectively. 